\title{
ANÁLISE DE GRUPOS ESTRATÉGICOS E DESEMPENHO NA INDÚSTRIA DE BANCOS COMERCIAIS NO BRASIL
}

\section{STRATEGIC GROUPS AND PERFOMANCE ANALYSIS IN THE COMMERCIAL BANKING INDUSTRY IN BRAZIL}

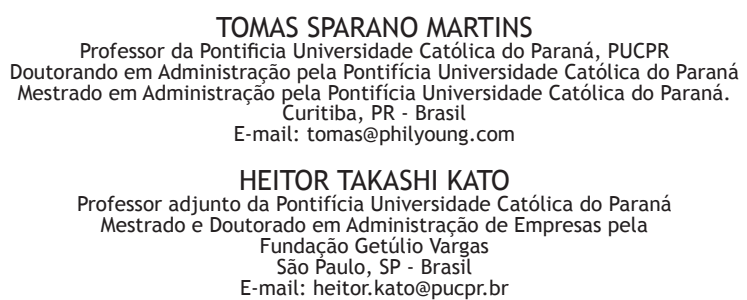

JUNE ALISSON WESTARB CRUZ

Professor da Pontificia Universidade Católica do Paraná, PUCPR Doutorando em Administração pela Pontifícia Universidade Católica do Paraná Mestrado em Administração pela Pontifícia Universidade Católica do Paraná.

$$
\text { E-mail: june.cruz@junecruz.com }
$$

WESLEY VIEIRA DA SILVA

Professor da Pontifícia Universidade Católica do Paraná, PUC-PR. Doutorado em Engenharia de Produção pela Universidade Federal de Santa Catarina. Curitiba, PR - Brasil
E-mail: wesley.vieira@pucpr.br

EDUARDO DAMIÃO DA SILVA

Professor da Pontifícia Universidade Católica do Paraná PUC-PR, Brasil. Doutor pelo Programa Ph D In Management Sciences pela Escuela Superior de Administración y Dirección de Empresas. Curitiba, PR - Brasil
E-mail: eduardo.damiao@pucpr.b

\section{RESUMO:}

O objetivo do presente trabalho é identificar a relação entre grupos estratégicos e desempenho na indústria de bancos comerciais no Brasil. Para cumprir esse propósito, foi realizado um estudo no setor, de janeiro a dezembro de 2007, com uma amostra não probabilística de 28 bancos, por meio da análise fatorial, da análise de cluster e da comparação descritiva de médias. A análise cluster indicou a presença de quatro grupos estratégicos: um grupo formado por 22 bancos (Grupo 1); outro formado pelos dois maiores bancos comerciais do Brasil (Grupo 2); um formado somente pelo Banco do Brasil (Grupo 3); e um formado por três bancos comerciais privados (Grupo 4). Pôde-se verificar que o Grupo 2 buscou uma estratégia baseada em seus recursos financeiros, o que the permitiu adotar uma estratégia de posicionamento relacionada a custo. 0 Grupo 3 adotou uma estratégia baseada em diversidade e qualidade de produtos, com atuação geográfica ampla. O Grupo 4, uma estratégia de diferenciação com uma amplitude geográfica relativamente alta. Com base nos indicadores de desempenho ROA e pelo ROE, o Grupo 2 (Itaú e Bradesco) apresentou um desempenho superior em retorno sobre ativos e o Banco do Brasil (Grupo 3), em retorno sobre o patrimônio líquido.

Palavras-chave: Bancos Comerciais, Grupos Estratégicos e Desempenho.

\section{ABSTRACT:}

This paper's objective is to identify the relationship between strategic groups and performance in the Brazilian private banking industry. In order to reach this objective, a study was conducted in the industry of commercial banks in Brazil, from January to December 2007, in a sample of 28 banks, through factor analysis, cluster analysis and a comparison of descriptive averages. The cluster analysis indicated the presence of four strategic groups: a group of 22 banks (Group 1), another formed by the two largest commercial banks in Brazil (Group 2), one formed only by the Bank of Brazil (Group 3) and one formed by three private commercial banks (Group 4). We could see that the Group 2 sought a strategy based on its financial resources, enabling it to adopt a cost related positioning strategy. Group 3 adopted a strategy based on product diversity and quality, with a geographically broad scope. Group 4 chose a strategy of differentiation with a relatively large geographic scope. Based on performance indicators ROA and ROE, Group 2 (Itau and Bradesco) showed superior performance in return on assets and the Bank of Brazil (Group 3) in return on equity.

Keywords: Commercial Banks. Strategic Groups. Performance. 


\section{INTRODUÇÃO}

O sistema bancário no Brasil passou por diversas mudanças nos últimos anos, especialmente a partir da estabilização da moeda promovida pelo Plano Real, implementado em 1994. Várias organizações estrangeiras aumentaram sua participação no setor e vários bancos estatais deixaram de funcionar, principalmente devido às privatizações ocorridas em decorrência da reestruturação produtiva efetuada no país na década de 1990.

Como destaca Belaisch (2003), o Plano Real trouxe à tona uma série de ineficiências do setor produtivo que resultou em altas taxas de inadimplência nos empréstimos bancários. Isso, somado ao fim da receita inflacionária, à abertura do mercado às instituições estrangeiras, a alterações nas regras de fiscalização e a ações do Banco Central - como o Programa de Estímulo à Reestruturação e ao Fortalecimento do Sistema Financeiro Nacional (PROER), o Programa de Apoio à Infra-Estrutura Econômica e Social (PROES) e o Programa de Reestruturação dos Bancos Federais (PROEF) -, vem aumentando o nível de competição no segmento e, consequentemente, ganhando relevância na análise estratégica, pois, como destaca Assaf Neto (200, p. 17), "para atuar em ambiente de concorrência, as instituições financeiras desenvolvem suas estratégias de mercado visando maximizar seus resultados operacionais."

Sobre o setor bancário brasileiro, Belaisch (2003), baseada em pesquisa empírica, cujos resultados indicam que os bancos brasileiros se comportam de forma oligopolística, observa ainda que o mesmo não é plenamente competitivo.

Recentemente, o cenário macroeconômico para essa indústria tem a seguinte configuração: juros em queda, câmbio flutuante, inflação baixa, assim como diminuição do risco-país e um programa de governo com ênfase no crescimento econômico. As mudanças no setor e este novo cenário obrigaram as instituições financeiras a se adaptarem a essas novas condições, onde a concepção e a execução de estratégias competitivas são essenciais para obtenção de um desempenho satisfatório e sustentável (WORLD BANK, 2007).

Entender este novo cenário é uma atividade inerente à estratégia competitiva de qualquer empresa que atua no setor. Porter (1996) definiu estratégia competitiva como a escolha deliberada de um conjunto de atividades, diferentes dos concorrentes, para a entrega de um produto ou serviço de valor exclusivo. As empresas, portanto, adotam estratégias variadas, levando em conta as diversas dimensões que vão determinar as opções relevantes para sua indústria. Segundo Porter (1980), são três as abordagens estratégicas genéricas: diferenciação, liderança em custo e enfoque; esta última tendo ramificações em custo ou diferenciação. Porém, todas elas podem ser adotadas por quaisquer empresas; tendendo ao sucesso quando implementadas corretamente. Quando despontam no mercado ações idênticas ou similares às já existentes, formam-se grupos estratégicos.

O estudo de grupos estratégicos surgiu com o objetivo de analisar o ambiente competitivo da indústria. A heterogeneidade da indústria permite avaliar as diferenças 
existentes entre as empresas e ao mesmo tempo identificar dentro de grupos certo grau de homogeneidade. Os grupos estratégicos são empresas que competem na mesma indústria com combinações similares de estratégia (HATTEN; SCHENDEL; COOPER, 1978). A identificação de grupos estratégicos possibilita, então, a compreensão de como diferentes empresas competem em uma indústria; podendo explicar, entre outros fatores, as diferenças de lucratividade dentro dos setores (COOL; DIERICKX, 1993; FIEGENBAUM; THOMAS, 1993).

Já Barney (2001), defensor do resource-based view, afirma que, para conseguir vantagem competitiva sustentável, as empresas devem buscar reunir recursos únicos de difícil imitabilidade e, dessa forma, criar produtos ou serviços que sejam diferenciados. Portanto, o desempenho da empresa não teria qualquer relação com as variáveis ambientais externas à empresa.

Este trabalho tem o objetivo de estudar a indústria de bancos comerciais no Brasil, tendo como foco as estratégias adotadas pelas empresas, buscando identificar a importância da estratégia adotada para melhorar o desempenho, bem como na obtenção e manutenção das vantagens competitivas. Para tanto, o estudo tem as seguintes questões intermediárias: (1) identificar quais variáveis estratégicas e de desempenho são relevantes, (2) estabelecer os grupos estratégicos e (3) analisar as diferenças entre estratégias e desempenho nos grupos, para compreender melhor as possíveis razões de sucesso na referida indústria - sucesso aqui concebido como desempenho financeiro.

Sob o ponto de vista prático, este trabalho pretende fornecer um entendimento sobre o posicionamento estratégico e suas implicações no desempenho dos bancos comerciais que atuam no Brasil. A expectativa do estudo é que os resultados aqui encontrados sejam relevantes para o conhecimento acerca da dinâmica competitiva dessa indústria.

Do ponto de vista teórico-empírico, é relevante para o meio acadêmico por se tratar de mais um teste do conceito de grupos estratégicos em uma indústria específica e da revisão de outros conceitos e modelos relativos à estratégia. A grande maioria das pesquisas busca a comparação de desempenho entre grupos estratégicos (Caves e Porter, 1977; McGee e Thomas, 1986; Thomas e Venkatraman,1988; Fiegenbaum e Thomas, 1990; Nair e Kotha,

2001) e que, nos últimos anos, foi investigada numa variedade de setores: setor hoteleiro na Espanha (Claver-Cortes, et. al 2009), indústria farmacêutica britânica (Leask e Parker, 2007), indústria farmacêutica americana (Erden et. al. 2009), terceiro setor nos Estados Unidos (Marlin, Ritchie e Geiger, 2009) industria de semicondutores em Taiwan (Cheng, Chang e Hae-Ching, 2009), varejo norteamericano (Shah, 2007) e indústria da construção civil na Turquia (Dikmen et. al. 2009), entre outros.

Espera-se então contribuir com a discussão sobre o poder explanatório do conceito de grupos estratégicos particularmente em relação a sua adequabilidade como forma de avaliação das estratégias no setor bancário brasileiro. 


\section{REFERENCIAL TEÓRICO}

A fundamentação teórica envolve os conceitos que compõe o modelo de análise do trabalho. Primeiramente, apresenta-se o conceito de estratégia, que é subdividido em análise estrutural da indústria, estratégias competitivas, visão baseada em recursos e grupos estratégicos; e, na sequência, o conceito de desempenho financeiro.

\subsection{ESTRATÉGIA}

Inicialmente, faz-se mister definir o termo estratégia. Na literatura sobre esta temática, não existe uma definição única e universalmente aceita para o conceito de estratégia. Mintzberg (1998), por exemplo, define estratégia de cinco maneiras diferentes: plano, manobra, padrão, posição e perspectiva. A estratégia, na opinião de Mintzberg (1998), é o guarda-chuva sob o qual estes conceitos se desenvolvem e se interrelacionam. Como manobra, ela pode ser considerada um movimento de um jogo com o propósito de "enganar" o competidor ou oponente, ou seja, é uma ação específica. As outras quatro definições possuem características mais particulares e relevantes e são apresentadas a seguir.

A estratégia como plano é o curso de ação conscientemente intencionado. Em outras palavras, é a estratégia realizada com antecedência às ações, as quais são aplicadas e desenvolvidas deliberadamente. A finalidade das ações é atingir os objetivos e metas previamente definidos pela organização.

Como padrão, é um modelo no qual as ações fluem, englobando o resultado de um comportamento intencionado ou não. Esta estratégia pode imputar uma intenção nesta consistência comportamental; existe um plano por trás do padrão de comportamento.

A estratégia como posição é o elo entre a organização e o ambiente, ou seja, entre o contexto interno e externo à empresa. Refere-se ao posicionamento da mesma no ambiente competitivo, encorajando a organização a encontrar a sua posição na indústria e protegê-la, de forma a enfrentar a competição, evitá-la ou subvertê-la. Uma posição pode ser previamente selecionada e planejada e/ou pode ser atingida de maneira emergente.

A definição de estratégia como perspectiva volta-se para dentro da organização; mas também é a maneira com que ela percebe o mundo. Dessa forma, torna-se o comprometimento com certas maneiras de agir; e é um conceito compartilhado pelos membros da organização, evidenciado em seus princípios e valores. Fahey (1999) ressalta que nenhuma definição é melhor que a outra, pois elas competem e se complementam. Ademais, nem todos os planos se tornam padrão e nem todos os padrões desenvolvem-se planejadamente. Algumas manobras são menos do que posições, enquanto outras estratégias são mais do que posições e menos que perspectivas. Cada definição adiciona elementos importantes ao entendimento de estratégia. 
Para Child (1972, p. 18), estratégia é "um termo usado para demonstrar a questão da importância para uma organização como um todo, particularmente os entendimentos sobre sua habilidade para prosperar dentro de um ambiente onde se enfrenta a competição e precisa-se manter a credibilidade. Está estreitamente relacionado à idéia de estratagema, que é a maneira pela qual se procura concluir um objetivo em interação com ou contra outros”.

Ansoff (1988) desenvolveu o conceito de estratégia corporativa, ressaltando a necessidade de apresentação de diretrizes específicas para orientar sua direção, com objetivos e regras de decisão que limitem o processo de escolha da empresa às oportunidades. Andrews (1971), paralelamente, define estratégia coorporativa como um modelo de decisões de uma empresa que determina seus objetivos e desenvolve normas e planos para alcançá-los. O referido autor observava a estratégia como um relacionamento dos pontos fortes e fracos da empresa com as oportunidades e ameaças do ambiente externo. Para ele, a adequação entre as capacidades únicas de uma empresa e as exigências de um setor era o que a distinguia das demais.

Hofer e Schendel (1978) entendem que a estratégia conecta uma organização a seu ambiente por meio de um caminho que a leva a alcançar suas metas e objetivos. Isso ocorre em três níveis: corporativo, unidade de negócios (competitiva ou organizacional) e funcional, no qual a estratégia corporativa preocupa-se com o tipo de negócio que a empresa pretende atuar e a estratégia competitiva, com o posicionamento da organização no ambiente e o modo de como competir neste ambiente. A estratégia competitiva foi desenvolvida para analisar como as organizações devem se posicionar e competir eficientemente em seu negócio. A estratégia funcional está relacionada com a forma que os componentes da organização, em termos de recursos, processos, pessoal e suas habilidades efetivamente vão contribuir para orientar a empresa para a direção das estratégias da unidade de negócios e corporativa.

Em outra linha de pensamento, Prahalad e Hamel (1990) fazem uma abordagem que enfatiza o foco interno da estratégia. A ideia é que a competência essencial da organização constitui sua vantagem competitiva sustentável. Por competência essencial, eles entendem o aprendizado contínuo da organização, a capacidade de integrar diferentes tecnologias, o grau de comunicação, envolvimento e comprometimento verificado entre os integrantes da organização.

Para analisar a competitividade existente no ambiente da indústria, surgiu também a teoria dos grupos estratégicos. Entretanto, esta teoria não teve sua origem na estratégia, mas, sim, nos estudos de economistas da Organização Industrial. Pela análise dos grupos estratégicos, muitos pesquisadores da área de Administração Estratégica podem verificar o relacionamento entre estratégia e desempenho nas empresas, e por que algumas estratégias obtêm êxito e outras não (FIEGENBAUM; THOMAS, 1993)

\subsection{ANÁLISE ESTRUTURAL DA INDÚSTRIA}

O modelo SCP (structure-conduct-performance) tem servido como base para 
muitos trabalhos relacionados à estrutura da indústria, incluindo as teorias de Porter (1980). De acordo com esse modelo, o desempenho das empresas em determinada indústria depende da definição de estratégias como fixação de preços, produto e publicidade, pesquisa e desenvolvimento, programa de investimentos e táticas legais (por exemplo, o direito de patente) diante do comportamento dos consumidores e dos fornecedores. Essas definições são regidas pela estrutura da indústria, caracterizada por fatores como o número e o tamanho relativo dos concorrentes, consumidores e fornecedores, barreiras de entrada, grau de diferenciação dos produtos e grau de integração vertical. A ideia básica do SCP é que o desempenho das empresas é o resultado direto da adoção de estratégias competitivas, e que esse comportamento depende da estrutura da indústria na qual as empresas estão inseridas (BARNEY, 2001).

Comparativamente ao modelo SCP, Porter (1980) observa que o desempenho das empresas é fortemente influenciado pela estrutura da indústria e que a estratégia adotada interfere diretamente na estrutura, influenciando indiretamente o ambiente competitivo. O autor afirma que o desafio da empresa na busca por um melhor desempenho está na formulação de uma estratégia competitiva que lhe conceda vantagem ao se relacionar com seu meio ambiente.

Ainda segundo Porter (1980), essa vantagem competitiva é estabelecida quando a empresa realiza um conjunto de atividades necessárias para obter um custo mais baixo em relação ao dos demais participantes da indústria, ou executa essas atividades gerando um valor diferenciado para os consumidores de forma sustentável e superior a de suas rivais. A elaboração de uma estratégia eficaz exige a percepção do ambiente competitivo da indústria, assim como as características que governam suas forças competitivas. Porter (1980) desenvolveu um modelo para suportar a formulação de estratégias mediante a investigação das forças que atuam no ambiente competitivo com o potencial de ameaçar o desempenho das empresas.

\subsection{ESTRATÉGIAS COMPETITIVAS GENÉRICAS}

A estratégia competitiva pode ser definida como a forma pela qual a organização usa estratégia para adaptar-se e/ou mudar aspectos do ambiente para chegar a um alinhamento mais favorável.

Uma maneira de se analisar estratégia competitiva é usar uma abordagem classificatória que tenda a agrupar a estratégia em grupos previamente definidos ou categorias derivantes. Esta abordagem, geralmente referida como tipologias ou taxinomias, agrega firmas de acordo com a natureza da estratégia enfatizada (MORGAN; STRONG, 1998); como, por exemplo: Porter, 1985; Hofer e Schendel, 1978; Miles e Snow, 1978. Especificamente, segundo Herbert e Deresky (1997, apud Gimenez et al. 1998), uma estratégia genérica pode ser definida como uma categorização ampla de escolhas estratégicas com aplicação generalizada em diversas indústrias.

Classificar algo é conhecer um ou dois atributos-chave de um objeto e então 
fazer uma dedução sobre outras características. Para Hambrick (1984), a classificação é especialmente importante para o estudo de estratégias organizacionais, uma vez que as estratégias resultam da integração de várias dimensões que podem ser combinadas de maneira múltipla e interminável. Destarte, sem uma classificação, o pesquisador terá que lidar individualmente com muitas variáveis e se contentar com o fato de que todas as combinações são possíveis.

\subsubsection{MODELO DE PORTER}

Porter (1980) apresenta um modelo que determina a intensidade de competição dentro da indústria, o nível de lucratividade e a estratégia da empresa, a partir de cinco forças competitivas, a saber: poder de negociação dos fornecedores, ameaça de novos entrantes, ameaça de produtos e serviços substitutos, poder de negociação dos compradores e rivalidade entre as empresas existentes.

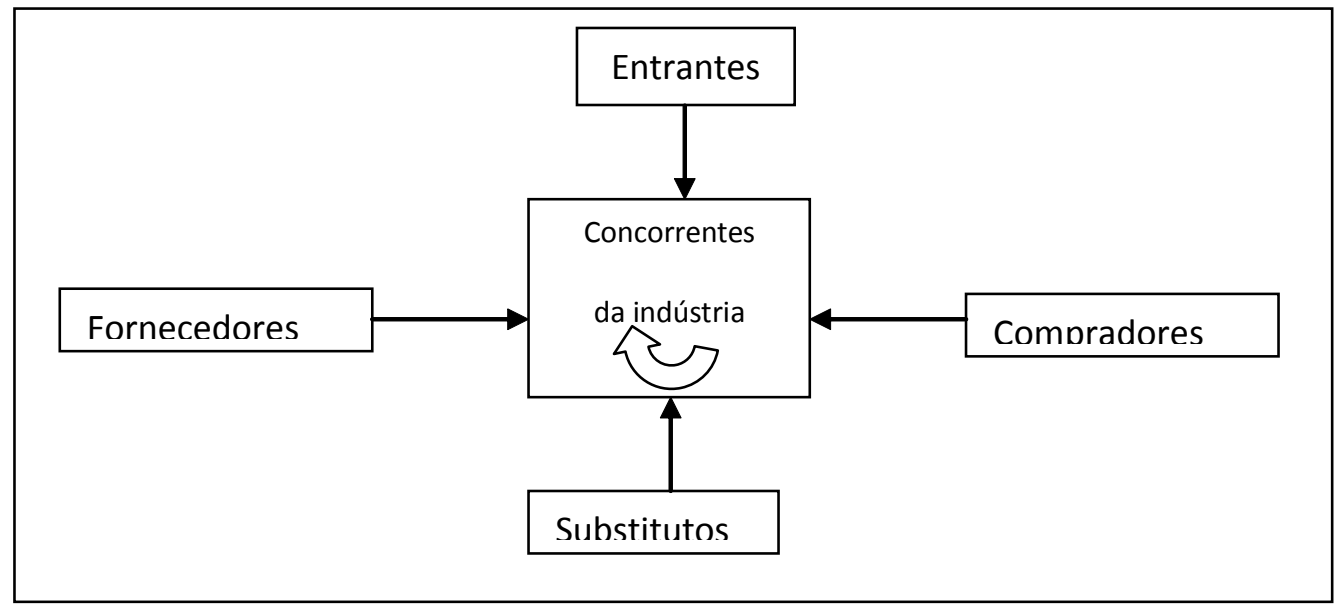

Figura 1 - Forças competitivas que dirigem a concorrência da indústria

Fonte: Porter (1980)

Para o autor, formular uma estratégia competitiva é encontrar uma posição no ambiente onde a organização possa estar mais bem protegida das forças competitivas e obter uma vantagem em relação aos seus competidores. Assim, é importante entender o conceito das forças e sua relativa intensidade, segundo Porter (1980) explica:

- Poder de negociação dos fornecedores: um grupo de fornecedores é poderoso quando é dominado por poucas companhias; não está obrigado a lutar com outros produtos substitutos; a indústria não é cliente importante para o fornecedor; o produto do fornecedor é um insumo importante para o negócio do comprador; os produtos são diferenciados; e representa uma ameaça concreta de integração para frente.

- Ameaça de novos entrantes: diz respeito a novas empresas que trazem novas capacidades e recursos para uma indústria com o objetivo de ganhar parcela 
de mercado. A ameaça depende das barreiras existentes; se forem altas, o recém-chegado encontrará retaliação acirrada dos concorrentes já instalados e não se constituirá uma ameaça.

- Poder de negociação dos compradores: compradores competem exigindo preços baixos e qualidade, jogando os concorrentes uns contra os outros. Um grupo de compradores é poderoso quando: está concentrado ou adquire grandes volumes em relação às vendas; os produtos que adquire representam uma fração significativa das suas próprias compras; os produtos são padronizados e não diferenciados; há poucos custos de mudança; consegue lucros baixos; há ameaça concreta de integração para trás; o produto da indústria não é importante para a qualidade dos produtos ou serviços do comprador; e o comprador tem total informação sobre a transação. A empresa, segundo Porter (1980) deve adotar como parte de sua estratégia, a escolha dos grupos de compradores a quem vender.

- Ameaça de serviços ou produtos substitutos: substitutos são aqueles produtos que desempenham a mesma função daqueles da indústria. Frente a essa ameaça, Porter (1980) salienta que a indústria pode se posicionar coletivamente por meio de ações conjuntas contra substitutos. Ademais, deve-se prestar mais atenção a substitutos que estão sujeitos a melhoramento do seu trade off e que são produzidos por indústrias lucrativas.

- Rivalidade entre empresas existentes: a rivalidade entre os concorrentes de uma indústria pode ser definida como a disputa por posição entre as empresas que já atuam em um mesmo mercado. Ela é caracterizada pelo uso de táticas como: concorrência de preços, batalha de publicidade, introdução e aumento dos serviços ou das garantias dos compradores (PORTER, 1986). A intensidade da rivalidade pode ser analisada levando-se em consideração a interação de vários fatores, que são: concorrentes numerosos e bem equilibrados; crescimento lento da indústria, custos fixos ou de armazenamento altos; ausência de diferenciação ou custos de mudança; capacidade da produção aumenta em grandes incrementos; concorrentes divergentes; grandes interesses estratégicos; barreiras de saídas elevadas.

A concorrência é determinada pelas forças competitivas e a partir da análise de cada uma delas pode-se traçar um plano de ação que incluirá: o posicionamento da organização, de forma que as suas capacitações forneçam as melhores defesas contra essas forças, e/ou a influência sobre o equilíbrio das forças por meio de movimentos estratégicos para melhorar a posição competitiva e/ou antecipação de mudanças.

Porter (1980) sugere três estratégias competitivas genéricas para enfrentar as forças competitivas, criando uma posição defensável no longo prazo e superando os concorrentes na indústria: liderança em custo, em diferenciação e enfoque.

$\mathrm{Na}$ liderança de custo, a empresa visa ser o produtor de mais baixo custo na indústria, o que lhe permite praticar preço inferior ao da concorrência e manter margem de lucratividade. Ela deve ser "a" líder no custo; ela comanda os preços da indústria, mas precisa de paridade ou proximidade com a diferenciação relativa aos 
seus concorrentes.

Com a estratégia de diferenciação, a empresa visa ser a única em sua indústria em algumas dimensões amplamente valorizadas pelos compradores. Ela deve escolher atributos que sejam realmente diferentes. No entanto, precisa de paridade ou proximidade de custos em relação aos seus concorrentes, pois a diferença maior que consumidor está disposto a pagar pela diferença nem sempre representa um valor muito superior ao praticado pela média do setor.

Por exemplo, um consumidor aceita pagar um valor maior para ter os diferenciais de inovação e design de um produto Apple, mas esta diferença superior não é tão maior que o valor médio cobrado pelos concorrentes. Logo, para ter um preço de venda próximo aos concorrentes médios, a estrutura de custo da Apple não pode ser muito superior a média do setor.

O Enfoque é a busca de um segmento específico do mercado total, que pode ser definido pela singularidade geográfica, exigências especiais no uso do produto ou por atributos particulares do produto que têm força de apelo para um determinado e restrito público. Servindo a um mercado limitado, a empresa que utiliza a estratégia do enfoque pode buscar liderança em custos ou diferenciação neste segmento, com as mesmas vantagens e desvantagens dos líderes de custo e dos diferenciadores.

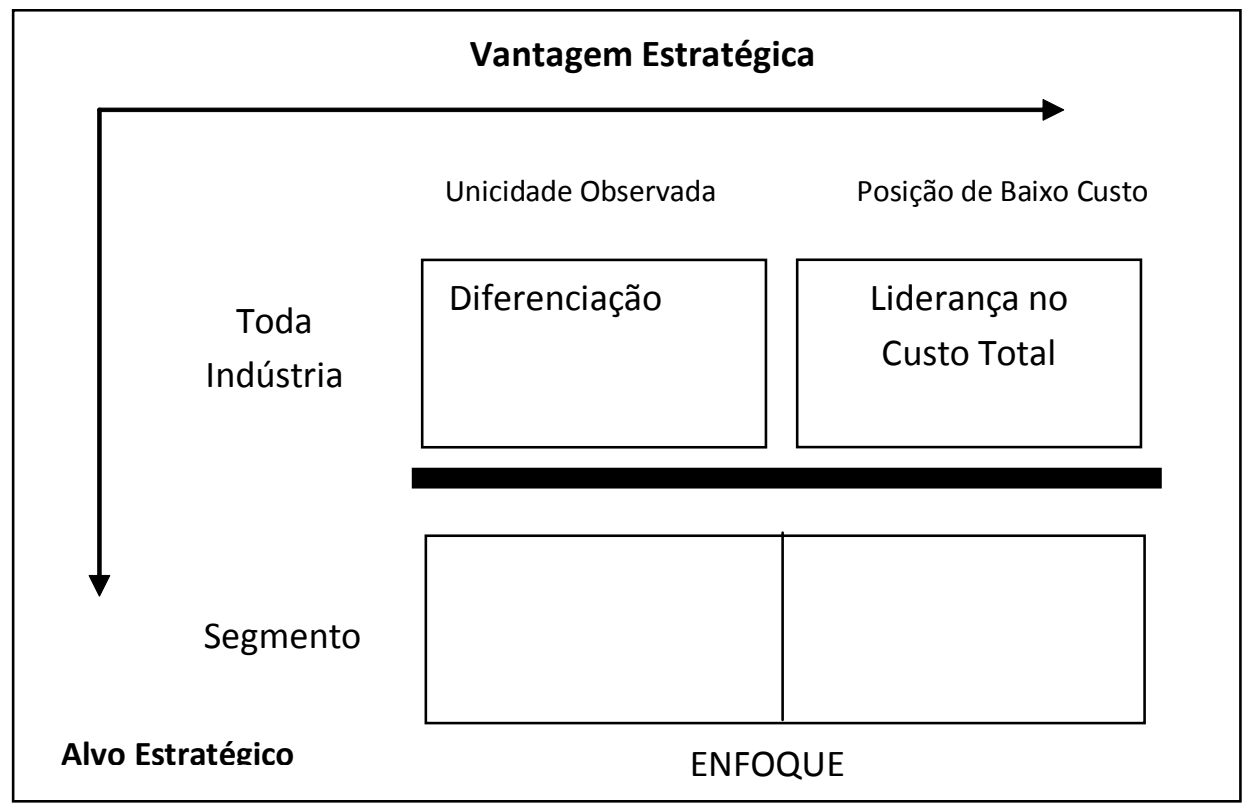

Figura 2: Três estratégias genéricas

Fonte: Porter (1980)

\subsection{A VISÃO BASEADA EM RECURSOS}

Segundo Foss (1996), foi na identificação das habilidades da empresa para se relacionar com o ambiente externo que Porter (1980) concentrou sua análise. Por esse motivo, o ambiente competitivo acabou sendo mais enfatizado que o organizacional. 
Entretanto, outra linha de pesquisa observou que os recursos internos às empresas também eram potenciais fontes de vantagem competitiva (WERNERFELT, 1984; BARNEY, 2002). A resource-based view (RBV) sustenta a ideia de que a principal fonte de vantagem competitiva está nos recursos e nas capacidades desenvolvidos e controlados pelas empresas e que a estrutura das indústrias nas quais elas se posicionam tem influência secundária (WERNERFELT, 1984; PETERAF, 1993).

Essa visão assume como premissas a heterogeneidade e a não imitabilidade dos recursos das empresas, consideradas como "feixes de recursos" (WERNERFELT, 1984) compostos por ativos, tangíveis e intangíveis. Um recurso deve possibilitar o emprego de estratégias que criem valor para a empresa, seja superando seus concorrentes, seja reduzindo suas fraquezas (BARNEY, 2002).

Para Prahalad e Hamel (1990), as empresas podem ser caracterizadas por um conjunto de competências e capacidades consideradas únicas, difíceis de imitar ou substituir. Estes autores utilizaram a expressão "competências essenciais" para se referir ao conhecimento coletivo da empresa na coordenação de suas habilidades de produção e no uso de tecnologias para aproveitar oportunidades ou se adaptar de forma ágil.

\subsection{GRUPOS ESTRATÉGICOS}

O estudo de grupos estratégicos como uma ferramenta analítica para examinar a estrutura dentro da indústria teve início com o trabalho de Hunt (1972), que procurou explicar a diferença de desempenho na indústria de eletrodomésticos da linha branca nos Estados Unidos. Ele definiu grupos estratégicos como um grupo de empresas equivalentes dentro de uma determinada indústria, em relação à estrutura de custo, grau de diversificação de produtos, organização formal, sistemas de controle, gerenciamento de recompensas e punições e visões pessoais e preferências para possíveis resultados (FIEGENBAUM; THOMAS, 1993).

Os grupos estratégicos podem ser definidos como uma série de empresas competindo dentro de uma indústria com base em combinações similares de estratégias, seja de domínio de mercado ou de alocação de recursos (COOL; SCHENDEL, 1998).

Diversos autores propuseram que empresas pertencentes a um mesmo grupo estratégico apresentassem desempenhos similares, enquanto os desempenhos de empresas de outros grupos foram significativamente diferentes (FIEGENBAUM; THOMAS, 1993).

A principal explicação das diferenças significativas de desempenho entre grupos estratégicos está baseada na Teoria da Organização Industrial, que estabelece que empresas pertencentes a indústrias diferentes têm diferente performance. Ao tomar a indústria como unidade de análise, a abordagem assumiu a premissa implícita que as empresas pertencentes a uma mesma indústria seriam todas iguais nas dimensões importantes para a análise econômica. A partir dessa perspectiva, empresas dentro dos grupos estratégicos fariam um conluio de forma a se isolar das demais empresas 
fora do grupo, criando barreiras de mobilidade que restringem a capacidade de as empresas fora do grupo adotarem posturas estratégicas semelhantes (PETERAF; SHANLEY, 1997; CAVES; PORTER, 1977; FIEGENBAUM; THOMAS, 1993).

Empresas em grupos diferentes estão submetidas a ambientes competitivos distintos com variados potenciais de rentabilidade, segundo Caves e Porter (1977); tais circunstâncias promovem heterogeneidade no desempenho entre grupos.

Para Porter (1980), um grupo estratégico é o grupo de firmas em uma indústria que segue a mesma estratégia ou estratégias similares ao longo das dimensões estratégicas. Ele afirma que as dimensões estratégicas desenhadas por esse grupo captam as diferenças possíveis entre as opções estratégicas de uma empresa: especialização, identificação de marcas, política de canal, seleção do canal, qualidade do produto, liderança tecnológica, integração vertical, posição de custo, atendimento, política de preço, alavancagem, relacionamento com a matriz e relacionamento com os governos do país de origem e anfitriões. Assim, para o autor, o grupo estratégico é um recurso analítico desenhado para ajudar em análise estrutural. Trata-se de uma referência intermediária entre olhar a indústria como um todo e considerar cada firma separadamente. Por meio do agrupamento, pode-se analisar a estrutura da competição específica do grupo, verificar sua atratividade e analisar a competição dentro e entre grupos.

\subsection{DESEMPENHO FINANCEIRO}

O conceito de desempenho está fortemente relacionado à estratégia. Barney (2001) conceitua desempenho como o resultado da comparação entre o valor criado pela organização e o valor esperado pelos acionistas. Se o resultado for satisfatório, os recursos continuarão disponíveis; caso contrário, os acionistas podem procurar formas alternativas de retorno. Assim, o autor sugere três possibilidades: desempenho normal (o resultado é equivalente ao esperado); valor superior (o resultado é superior ao esperado) e valor inferior (resultado abaixo do esperado).

Cool e Schendel (1998) sugerem o emprego de múltiplos indicadores para se obter uma avaliação consistente do desempenho, pois, segundo os autores, este é um conceito claramente multidimensional. Mehra (1996), para avaliar o desempenho na indústria financeira, utilizou os aspectos de rentabilidade e produtividade, seguindo a recomendação de Chakravarthy (1986) - que afirma que a mensuração do desempenho da empresa deve ser feita preferencialmente em caráter multidimensional.

Critérios objetivos de avaliação de desempenho, tais como retorno sobre investimento (ROI), retorno sobre vendas (ROS), retorno sobre ativos (ROA), crescimento de vendas e parcelas de mercado, dominam a literatura. Esses indicadores foram usados em diversos estudos de estratégia competitiva, tais como os realizados por Porter (1980), Dess e Davis (1984), Cool e Schendel (1998). 


\subsection{DESCRIÇÃO GERAL DA INDÚSTRIA FINANCEIRA NO BRASIL}

A indústria financeira no Brasil é composta por instituiçõos financeiras públicas e privadas cujo objetivo é manter um fluxo de recursos entre investidores e tomadores de empréstimos recursos (Almeida et al., 1998). Segundo Fortuna (2001) algumas instituições públicas têm funções reguladoras e administradoras da política econômica. Além do Conselho Monetário Nacional (CMN), que determina e supervisiona as diretrizes da política monetária, crédito e câmbio do país, o governo brasileiro controla as seguintes instituições: Banco Central do Brasil, responsável pela execução das decisões do CMN, normatização e fiscalização do sistema financeiro nacional; Banco do Brasil, principal agente financeiro e creditício do governo, que é o maior banco comercial no Brasil; BNDES, um banco de desenvolvimento que oferece financiamento de médio e longo prazo ao setor privado brasileiro, principalmente, para a indústria; Caixa Econômica Federal (CEF), que especialmente faz a captação de depósitos e fornece financiamento imobiliário e de infra-estrutura urbana.

Algumas outras instituições financeiras controladas pelo governo, como os bancos comerciais públicos, possuem um papel importante na indústria financeira brasileira. Estas instituições atuam intensamente em mercados que os bancos privados costumam dar menor prioridade, como o financiamento imobiliário e empréstimos agrícolas. Os bancos de desenvolvimento estaduais também têm um papel importante, proporcionando o suprimento de recursos necessários ao financiamento de projetos para promover o desenvolvimento econômico e social regional.

Os principais tipos de instituições financeiras privadas são:

a) Bancos Comerciais, que atuam principalmente nas atividades bancárias de varejo e atacado, com foco na captação de depósitos a vista e a prazo e no financiamento de capital à indústria, ao comércio e ao público em geral. Estes bancos também oferecem serviços como cobrança de títulos e ordens de pagamento, arrecadação de impostos e taxas, guarda de valores entre outros;

b) Bancos de Investimento que atuam principalmente na colocação e a distribuição de valores mobiliários e na estruturação de transações.

c) Bancos múltiplos, que oferecem uma gama completa de serviços de banco comercial, banco de investimento (incluindo colocação, distribuição e corretagem de valores mobiliários), crédito ao consumidor e outros.

As instituições podem ainda ser caracterizadas quanto ao tipo de atividade que exercem. Bancos varejistas costumam apresentar elevado número de agências, abrangendo uma grande amplitude geográfica e oferecendo todo tipo de produto para uma grande quantidade de clientes. Por outro lado, os bancos especialistas, ou atacadistas atuam de forma especializada em segmentos específicos do mercado, normalmente oferecendo um número menor de produtos e serviços, porém, uma maior capacidade de diferenciação dos mesmos. 


\section{METODOLOGIA DA PESQUISA}

Este estudo quantitativo, quanto aos fins, e seguindo a taxonomia apresentada por Vergara (1997), pode ser classificado como descritivo, na medida em que expõe características dos grupos estratégicos que compõem a indústria de bancos comerciais no Brasil. Ainda, pode ser classificada ainda como explicativa, uma vez que identifica e analisa a relação existente entre as estratégias competitivas e a estrutura dos grupos estratégicos para esclarecer diferenças de desempenho.

No que diz respeito aos meios de investigação, ela atende à classificação de Vergara (1997): é bibliográfica, por fazer uso de livros, artigos, dentre outras publicações; documental, pela análise de documentos específicos, tais como demonstrações financeiras; telematizada, devido à coleta de informação na Internet.

\subsection{POPULAÇÃO E AMOSTRA}

Para realizar o estudo, foi usada uma amostra não probabilística, extraída da população composta por 129 instituições financeiras habilitadas a operar no país, no período de janeiro a dezembro de 2007, que constavam na base de dados elaborada pelo Banco Central do Brasil e pelo sistema Economatica. Para o critério de seleção, foram eleitas somente as instituições financeiras, independentes: banco comercial; banco múltiplo com carteira comercial que não integrassem um conglomerado; e conglomerados bancários com pelo menos uma instituição do tipo banco comercial ou banco múltiplo com carteira comercial. Das 129 empresas da população, 25, todas estrangeiras, realizavam apenas atividades de investimento; assim, estas foram descartadas para a análise. Das 104 que restaram, apenas 28 continham todas as informações necessárias para a elaboração deste estudo, atendendo o critério eleito.

\subsection{VARIÁVEIS: ESTRATÉGIA E DESEMPENHO}

Com base no trabalho de Coll e Schendel (1998) e Mehra (1996), as estratégias foram operacionalizadas a partir de indicadores relacionados ao escopo de atuação e à exploração de recursos das instituições-alvo da pesquisa. A revisão da literatura e as discussões com um gestor de bancos (especialista da indústria) contribuíram para que fosse possível identificar 13 variáveis representando estes componentes.

O compromisso com escopo foi medido na indústria a partir do escopo de produto, escopo geográfico e diversidade de produtos e serviços. 0 escopo de produto pôde ser inferido a partir de quatro variáveis: Depósitos à Vista (DV), Depósitos em Poupança (DPOUP), Depósitos a Prazo (DPRAZ) e Investimentos em Títulos e Valores Mobiliários (AITVM). O escopo geográfico foi medido a partir de duas variáveis: Número de Funcionários (NUMFUN) e Número de Agências (NUNAG). A diversidade 
de produtos, por sua vez, foi medida por uma variável: Receitas de Prestação de Serviços Não Relacionados a Juros (SERVIÇOS).

As variáveis estratégicas relacionadas a recursos foram baseadas em operações e finanças, pois representam duas áreas funcionais chaves, fortemente relacionadas às estratégias competitivas na indústria financeira. Decisões que determinam o grau de alavancagem e estratégias de financiamento e investimento indicam diferenças na forma como as empresas alocam recursos. Quatro medidas foram aplicadas para refletir essa diferenciação: Investimentos (INVEST), Patrimônio Líquido (PL), Ativo Permanente (ATVPERM) e ATIVO TOTAL.

Por fim, rentabilidade e produtividade foram os indicadores usados para avaliar o desempenho da indústria financeira, seguindo a recomendação de Chakravarthy (1986), utilizando-se da rentabilidade do patrimônio líquido (ROE) e da rentabilidade dos ativos (ROA).

\subsection{COLETA E ANÁLISE DOS DADOS}

Os dados foram coletados no Sistema de Informações do Banco Central (SISBACEN) e no sistema Economatica. A partir daí, montou-se uma base de dados que foi tratada e analisada quantitativamente com a utilização do software estatístico SPSS 14.0, cujos procedimentos adotados são explicitados a seguir.

\subsubsection{ANÁLISE FATORIAL}

Segundo Hair et. al. (2005), a análise fatorial é uma técnica estatística multivariada de simplificação da informação. Pelo agrupamento de variáveis, que estão altamente correlacionadas, elimina-se a informação considerada redundante. Deste modo, obtêm-se indicadores de síntese (fatores) que permitem ter em conta o máximo de informação relevante. Após o cálculo da matriz de correlações, testou-se a possibilidade de utilização da análise fatorial, recorrendo-se, para tal, ao teste de esfericidade de Bartlett e à estatística de Kaiser-Meyer-Olkin (KMO).

Em seguida, os fatores foram extraídos através do método dos componentes principais, que permitiram transformar um conjunto $p$ de variáveis correlacionadas entre si, em um novo conjunto $\mathrm{p}$ de variáveis não correlacionadas (ortogonais), as chamadas componentes principais, que resultaram de combinações lineares das variáveis originais.

Destarte, determinados os componentes principais, questionou-se qual o número de componentes a considerar. Para este efeito, foi utilizado o critério de Kaiser, no qual a matriz dos pesos fatoriais (loadings) indica as relações entre os fatores e as variáveis - e foi por meio dela que os componentes foram aqui interpretados. Por esse critério, quanto mais próximo de um (em valor absoluto) estiver esse peso, mais forte é a associação entre a variável e o componente. A etapa final da análise fatorial é estimar os valores dos fatores para cada uma das subseções 
estatísticas. Estas estimativas são necessárias para a representação cartográfica e para a análise subsequente, a análise de cluster.

\subsubsection{ANÁLISE DE CLUSTER}

Uma análise de cluster, segundo Hair (2005), é um conjunto de técnicas estatísticas cujo objetivo é agrupar objetos segundo suas características, formando grupos ou conglomerados homogêneos. Os objetos em cada conglomerado tendem a ser semelhantes entre si, porém diferentes dos demais objetos dos outros conglomerados. Os conglomerados obtidos devem apresentar tanto uma homogeneidade interna (dentro de cada conglomerado), como uma grande heterogeneidade externa (entre conglomerados).

Nesse sentido, esta análise foi utilizada para classificar e agrupar as instituições financeiras de maneira homogênea, tendo por base os componentes principais extraídos. Recorreu-se, então, a uma análise de clusters com base no algoritmo de Ward, que é um método hierárquico aglomerativo, uma vez que há tantos clusters quanto objetos. Em seguida, os objetos mais semelhantes foram agrupados, dando os " $n$ " clusters iniciais origem a n-1 clusters. Estes grupos iniciais foram fundidos, sucessivamente, com base nas suas semelhanças, até se formar apenas um cluster.

Em geral, este é considerado um método eficiente; e o inconveniente que mais frequentemente lhe é apontado é a formação de clusters de dimensão idêntica e reduzida. Em particular, o método de Ward distingue-se dos restantes porque recorre à análise da variância para avaliar a distância entre clusters. Este método sugere a fusão dos dois clusters que minimizam o incremento da soma de quadrados das distâncias em relação ao novo centróide total dos elementos pertencentes ao cluster.

\subsubsection{ANÁLISE DA VARIÂNCIA - ANOVA}

A análise da variância, ANOVA serve para comparar a igualdade das médias, pois esta compara a proporção relativa da variância, também designada por variância residual dentro dos grupos, com a variância, também designada por variância do fator, entre os grupos. Se a variância residual for, significativamente, inferior à variância entre os grupos, então as médias populacionais, estimadas a partir das amostras, são, significativamente diferentes (HAIR et. al., 2005).

\section{APRESENTAÇÃO E ANÁLISE DOS DADOS}

Os resultados são apresentados nas seções a seguir, por meio de tabelas e referidas explicações. 


\subsection{TESTE DE ADEQUAÇÃO}

A seguir, apresentam-se resultados obtidos utilizando-se os testes de adequação da medida da amostra - KMO e o teste de esfericidade de Bartlett - para a análise das variáveis. Ambos indicam a adequação dos dados para a realização da análise fatorial.

0 teste Kaiser-Meyer-Olkin (KMO) é uma estatística que indica a proporção da variância dos dados que pode ser considerada comum a todas as variáveis, ou seja, que pode ser atribuída a um fator comum, então: quanto mais próximo de 1 (unidade) melhor o resultado, ou seja, mais adequada é a amostra à aplicação da análise fatorial.

0 teste de esfericidade de Bartlett testa se a matriz de correlação é uma matriz identidade, o que indicaria que não há correlação entre os dados. Dessa forma, procura-se, para um nível de significância assumido em $5 \%$, rejeitar a hipótese nula de matriz de correlação identidade. Em todos os casos reportados abaixo, as amostras mostraram-se adequadas para a aplicação de análise fatorial $(K M O>0,5)$ e Bartlett com rejeição de hipótese nula.

Para se chegar ao resultado, quatro variáveis foram eliminadas do modelo: DV (Depósitos à Vista), SERVIÇOS (Receitas de Prestação de Serviços Não Relacionados a Juros), PL (Patrimônio Líquido) e ATIVO TOTAL.

0 teste de Bartlett mostrou-se significativo $(R=423,825$, sendo $p<0,0001)$, rejeitando a hipótese nula de que a matriz de correlação é uma matriz identidade. 0 teste de KMO, para a análise da adequabilidade da amostra, apresentou um valor de 0,756 , indicando que a amostra é passível de ser analisada pelas técnicas da análise fatorial.

Tabela 1 - Teste KMO e Bartlett

\begin{tabular}{|c|c|c|}
\hline \multicolumn{2}{|c|}{ Kaiser-Meyer-Olkin Measure of Sampling Adequacy. } & ,756 \\
\hline \multirow[t]{3}{*}{ Bartlett's Test of Sphericity } & Approximação Chi-Square & 423,825 \\
\hline & DF & 21 \\
\hline & Sig. & ,000 \\
\hline
\end{tabular}

Fonte: Dados da pesquisa.

\subsection{RESULTADO DA ANÁLISE FATORIAL}

A análise fatorial foi realizada com o objetivo de diminuir o número de variáveis e simplificar as análises sem perda significativa de informações. A análise de fatores foi feita com rotação ortogonal do tipo Varimax. A rotação ortogonal reduz a carga do primeiro fator e aumenta a dos demais em um número menor de variáveis, de modo a destacar os que possuem maior carga. Na seleção de fatores, foram definidos como entrada autovalores com valores iguais ou maiores que um.

A Tabela 2 mostra que foram extraídos dois fatores com um poder de explicação 
de aproximadamente $98,5 \%$ da variância total, resultado considerado adequado para a continuidade do estudo.

Tabela 2 - Resultado da Análise de Fatores

\begin{tabular}{|c|c|c|c|c|c|c|c|c|c|}
\hline \multicolumn{10}{|c|}{ Total Variance Explained } \\
\hline & & & & & & & & & \\
\hline 1 & 5,859 & 83,699 & 83,699 & 5,859 & 83,699 & 83,699 & 3,962 & 56,599 & 56,599 \\
\hline 2 & 1,039 & 14,849 & 98,548 & 1,039 & 14,849 & 98,548 & 2,936 & 41,949 & 98,548 \\
\hline 3 & 067 & ,956 & 99,503 & & & & & & \\
\hline 4 & , & 356, & 99,859 & & & & & & \\
\hline 5 & 006 & 081 & 99,940 & & & & & & \\
\hline 6 & 003 & 047 & 99,987 & & & & & & \\
\hline 7 & 001 & 013 & 100,000 & & & & & & \\
\hline
\end{tabular}

Fonte: Dados da pesquisa

A Tabela 3 mostra a matriz dos fatores para a estratégia reduzida após a rotação dos eixos. A observação dos dados da referida tabela deixa evidente que as variáveis DPRAZ (Depósitos à Prazo) e INVEST (Investimentos) tiveram influência significativa nos fatores - assim representando e balizando os demais para a posterior análise de cluster.

Tabela 3 - Carga dos fatores após rotação dos eixos

\begin{tabular}{|c|c|c|} 
& \multicolumn{2}{|c|}{ Component } \\
\hline & 1 & 2 \\
\hline DPOUP &, 885 &, 450 \\
\hline DPRAZ &, 989 &, 082 \\
\hline AITVM &, 742 &, 647 \\
\hline NUMFUN &, 855 &, 502 \\
\hline NUNAG &, 866 &, 478 \\
\hline INVEST &, 268 &, 961 \\
\hline ATVPERM &, 309 &, 951 \\
\hline
\end{tabular}

Fonte: Dados da pesquisa.

As informações contidas nas cargas permitiram a seguinte interpretação dos fatores:) Fator 1: esse fator agrupa as variáveis Depósitos em Poupança (DPOUP), DPRAZ (depósitos à prazo), AITVM (Investimentos em Títulos e Valores Mobiliários), NUMFUN (Número de Funcionários) e NUNAG (Número de Agências). As variáveis NUMFUN e NUMAG relacionam-se à rede de distribuição, enquanto a DPOUP está ligada ao mais tradicional investimento disponível no mercado financeiro brasileiro. Grande parte dos recursos captados pelas instituições financeiras em contas de poupança devem ser obrigatoriamente direcionados para operações de financiamento habitacional. Esse fator pode ser considerado como indicador de orientação para o mercado de varejo que consome esse tipo de produto, setor que requer uma rede maior de agências e mais funcionários, se comparado ao mercado de atacado. A carga da variável DPRAZ (depósitos a prazo) foi muito alta $(0,989)$ representando o posicionamento no mercado na análise de cluster; 
b) Fator 2: esse fator é representado pelas variáveis Investimentos (INVEST) e Ativo Permanente (ATVPERM), com cargas 0,961 e 0,951, respectivamente. A variável APERM indica o nível de investimento em ativos, como instalações, máquinas e equipamentos, que, atrelada a outra, pode indicar uma maior capacidade de oferta de serviços diferenciados. A carga da variável INVEST (investimentos) também foi muito alta $(0,961)$, representando a estratégia baseada em recursos. Consequentemente, com base nesses dois fatores, a análise de cluster agrupou empresas com estratégias baseadas nas suas competências internas ou com o seu posicionamento de mercado.

\subsection{RESULTADO DA ANÁLISE DE CLUSTER}

Os bancos foram agrupados de acordo com os fatores identificados pela análise fatorial, recorrendo ao método hierárquico aglomerativo, o Squared Euclidean Distance. Como método de agrupamento, o método de Ward foi o escolhido, pois permite minimizar a variância dentro dos grupos. Desta análise, foram identificados 4 grupos estratégicos. As empresas de cada grupo estão relacionadas na Tabela 4: há 22 empresas no Grupo Estratégico 1, duas empresas no Grupo 2, uma empresa (o Banco do Brasil) no Grupo 3 e três empresas no Grupo 4

Tabela 4 - Resultado do agrupamento

\begin{tabular}{|c|c|c|c|}
\hline Grupo 1 & Grupo 2 & Grupo 3 & Grupo 4 \\
\hline Abc Brasil & Bradesco & Banco do Brasil & Nossa Caixa \\
\hline Alfa Invest & Itaubanco & & Banco Santander \\
\hline Amazonia & & & Unibanco \\
\hline Banese & & & \\
\hline Banestes & & & \\
\hline Banrisul & & & \\
\hline Besc & & & \\
\hline Citibank & & & \\
\hline Credid Suisse & & & \\
\hline Cruzeiro Sul & & & \\
\hline Daycoval & & & \\
\hline Deutsche Bank S.A. & & & \\
\hline $\begin{array}{l}\text { Dresdner Bank Brasil } \\
\text { S.A. }\end{array}$ & & & \\
\hline BEP & & & \\
\hline HSBC & & & \\
\hline Indusval & & & \\
\hline JP Morgan Chase & & & \\
\hline Merc Brasil & & & \\
\hline Panamericano & & & \\
\hline Paraná & & & \\
\hline Pine & & & \\
\hline Sofisa & & & \\
\hline
\end{tabular}


Para finalizar, foi efetuada a validação dos resultados obtidos por meio da análise de variância “one way" ANOVA (Tabela 5). A hipótese nula - Ho, nesse caso, consiste em testar se as médias dos grupos são semelhantes e significativas, propiciando que se façam comparações bem fundamentadas sobre os escores observados para cada grupo. Avaliando-se os valores assumidos por $\mathrm{F}$, juntamente com os respectivos graus de liberdade, observou-se que estes se apresentam com valores superiores ao $\mathrm{F}$ crítico, implicando que existem diferenças entre os grupos. Os valores do teste $\mathrm{F}$ indicam que os fatores retidos são significativos para o agrupamento realizado.

Tabela 5 - Análise ANOVA

\begin{tabular}{|c|c|c|c|c|c|c|}
\hline & \multicolumn{2}{|c|}{ Cluster } & \multicolumn{2}{c|}{ Error } & F & Sig. \\
\hline & Mean Square & df & Mean Square & Df & & \\
\hline DPRAZ & 2496804688698230,000 & 2 & 22227109328213,600 & 23 & 1380,943 &, $000^{*}$ \\
INVEST & 1403366215265171,000 & 2 & 16406717325101,730 & 23 & 147,697 &, $000^{*}$ \\
\hline
\end{tabular}

Fonte: Dados da pesquisa.

$$
\mathrm{P}<0,05
$$

A Tabela 6 mostra as médias de cada indicador nos quatro clusters. Assim, percebe-se que o Grupo 3, o Banco do Brasil, tem uma média de quantidades maior do que os outros grupos em depósitos a vista, depósitos em poupança, investimentos em títulos e valores mobiliários, receitas de prestação de serviços não relacionados a juros e número de funcionários.

Tabela 6 - Final Cluster Centers

\begin{tabular}{|c|c|c|c|c|}
\hline & Grupo 1 & Grupo 2 & Grupo 3 & Grupo 4 \\
\hline DV & 4923691 & 21930050 & 43603278 & 3728183 \\
\hline DPOUP & 501983,9 & 31515370 & 49096227 & 8802163 \\
\hline DPRAZ & 1409478 & 20589657 & 74506262 & 16603585 \\
\hline AITVM & 1939531 & 66477315 & 68.057 .572 & 26230286 \\
\hline NUMFUN & 3261,273 & 71463 & 102668 & 21255,33 \\
\hline NUNAG & 103,2727 & 2818,5 & 4133 & 868,6667 \\
\hline SERVIÇOS & 24782,71 & 466801 & 4.570 .166 & 188123,3 \\
\hline ATIVO TOTAL & 217735827,5 & 373570418 & 416502965 & 117593122,7 \\
\hline PL & 13416668 & 32026087 & 26370992 & 8835513 \\
\hline INVEST & 276445,9 & 40261826 & 5.624 .350 & 5612335 \\
\hline ATVPERM & 551690,9 & 44213470 & 9.052 .924 & 6569979 \\
\hline ROA & 1,957143 & 2,25 & 1,6 & 1,4 \\
\hline ROE & 0,081818 & 0,1 & 0,2 & 0,133333 \\
\hline
\end{tabular}

Fonte: Dados da pesquisa.

Estes dados podem indicar uma estratégia de escopo baseado nos produtos e sua diversidade com atuação geográfica ampla. O Grupo 2 (Bradesco e Itaú), que contém os dois maiores bancos do país, possui médias superiores nos seguintes indicadores: ativo permanente, investimentos e patrimônio líquido. Esses indicadores, no modelo do presente trabalho, representam um estratégia mais baseada em recursos, o que possibilita sua forte atuação com base numa elevada escala de operação e uma atuação proporcionalmente baixa no mercado de títulos e valores mobiliários. 
O Grupo 1, bancos privados e públicos, com controle nacional ou estrangeiro, apresentou o maior número de empresas: 22 bancos. Destacando-se também quanto à heterogeneidade no escopo de atuação. De maneira geral, é um grupo com escopo amplo de atuação com equilíbrio entre aplicações e receitas tanto de crédito quanto de títulos e valores mobiliários.

Os bancos do Grupo 4 (Nossa Caixa, Santander e Unibanco) possuem elevada capilarização, com características similares às do Grupo 2 (Bradesco e Itaú); porém, com menor escala. É um grupo voltado para o mercado de varejo, possuindo escopo amplo de atuação com equilíbrio entre aplicações e receitas tanto de crédito quanto de títulos e valores mobiliários.

\subsection{DESEMPENHO ENTRE OS GRUPOS}

A Tabela 6 apresenta os resultados da diferença de médias das medidas de desempenho ROA e ROE. Analisando o desempenho em relação ao retorno sobre o patrimônio líquido (ROE), podemos perceber indicações de desempenho superior do Grupo 3 (Banco do Brasil). O segundo melhor resultado para essa dimensão foi o do Grupo 4 (Itaú e Bradesco), constituído de grandes conglomerados de controle atuando principalmente no varejo. A pior média de desempenho foi apresentada pelo Grupo 1. Em relação à variável Rentabilidade dos Ativos (ROA), os Grupos 2 e 1 apresentaram igualmente o melhor desempenho.

Voltando à base teórica, segundo a estratégia competitiva genérica de Porter, os grupos podem ser definidos da seguinte maneira:

Grupo 1 (formado por 22 dos 28 bancos da amostra): estratégia de foco, ou nicho, pois os bancos neste grupo buscam a atuação em um segmento específico, alguns pela singularidade geográfica, como os bancos estaduais, outros por exigências especiais em seus serviços como o Paraná banco que tem sua atuação baseada na concessão de crédito consignado a aposentados pelo INSS, ou por atributos particulares do produto que têm força de apelo para um determinado e restrito público, como os bancos Credid Suisse, Deutsche Bank S.A. e Dresdner Bank Brasil S.A, que prestam serviços para um consumidor exclusivo. Neste grupo, o HSBC e Citibank chamam a atenção porque, teoricamente, não têm uma estratégia de foco, haja vista a amplitude de seu portfólio de serviços e escopo amplo de atuação. Diante disso, sua maneira de atuar lhes credenciasse a participar do Grupo 4, mas talvez a falta de uma definição de sua estratégia resulta em uma fragmentação de suas intenções, o que faz com que fiquem no grupo mais competitivo do setor.

Grupo 2 (formado pelo Itau e Bradesco): é o grupo dos dois maiores bancos comerciais do Brasil. Segundo a classificação de Porter (1980), estes dois bancos adotam uma estratégia de liderança de custo, pois visam produzir seus serviços com o custo mais baixo do setor. Conseguem atingir este objetivo devido à economia de escala, resultante da padronização e volume de seus serviços, este grupo possui o maior número de agências e funcionários do setor, o que teoricamente, lhes proporciona uma atuação geográfica extensa e intensa, gerando volume de uma forma padronizada, ou seja, em escala, que conseqüentemente, gera liderança de 
custo.

Grupo 3 (Banco do Brasil), se o presente estudo não estivesse limitado aos bancos comerciais, a Caixa Econômica provavelmente seria o concorrente natural do Banco do Brasil. Para analisar o motivo deste banco estar em uma posição tão privilegiada, ou seja, sozinho em um grupo, recorremos a outra base teórica, visão baseada em recursos. Segundo Barney (1991), uma empresa possui vantagem competitiva sustentável quando possui um recurso valioso, raro, difícil de imitar e difícil de substituir. O Banco do Brasil, assim como a Caixa Econômica, é o maior agente de crédito do governo, ou seja, este recurso, ter o apoio e representar o governo em várias situações, lhe proporcional vantagem competitiva sustentável.

Grupo 4 (Nossa Caixa, Santander e Unibando), na lógica de Porter (1980) adotam a estratégia de diferenciação, pois visam proporcionar aos compradores diferenças que justifiquem um preço superior. Em termos gerais, os três bancos procuram prestar um serviço exclusivo para seus clientes, fugindo da estratégia varejista do Grupo 2 e da estratégia tão focada do Grupo 1. O interessante é notar que o Nossa Caixa e o Unibanco foram incorporados pelo Banco do Brasil e Itaú, respectivamente. O Santander, recentemente, comprou o Banco Real, o que the proporcionou uma amplitude maior, talvez desvirtuando a sua estratégia de diferenciação.

\section{CONCLUSÃO}

Segundo Cardoso (2008), a importância do setor financeiro e bancário para o bom funcionamento da economia de qualquer país e a consequente necessidade de solidez de suas instituições justificam a relevância desta pesquisa. Um divisor de águas para o setor bancário brasileiro na história brasileira recente foi a implantação do Plano Real, em 1994, que, como destacado anteriormente, além de ter favorecido a emergência de uma série de ineficiências do setor produtivo que resultou em altas taxas de inadimplência nos empréstimos bancários, pôs fim à receita inflacionária e, com a abertura do mercado às instituições estrangeiras e alterações nas regras de fiscalização e a implementação dos programas PROER, PROES e PROEF, propiciou também o aumento do nível de competição no setor e o desenvolvimento de estratégias de mercado visando a maximização dos resultados operacionais.

A partir da análise dos dados percebeu-se que o Banco do Brasil, muito por suas características particulares, posiciona-se com uma estratégia de diversidade e qualidade de produto e com uma atuação geográfica ampla.

O Grupo 2 está posicionado com base em seus recursos evidenciados por uma grande quantidade de Ativos e alto índice de Patrimônio Líquido, o que permite um atuação ampla geograficamente e de varejo, muito baseada em custo.

O Grupo 1 foi agrupado baseado principalmente com base nos recursos e em uma estratégia de diferenciação de atuação estreita. Talvez, uma possibilidade para alguns bancos quebrarem esta intensidade competitiva seria a adoção de uma estratégia de foco, afunilando sua atuação e usando os seus recursos de maneira 
que estes pudessem proporcionar vantagem competitiva sustentável. 0 Grupo 4, como não possui uma base de recursos tão forte como a do Grupo 2, está em uma posição intermediária entre o Grupo 1 e o 2, o que lhe possibilita concorrer com uma estratégia de diferenciação e amplitude.

À luz dos resultados encontrados, uma das sugestões que se pode fazer é que estudos semelhantes a este sejam realizados em outros momentos no futuro, pois a indústria bancária brasileira vem passando por um intenso processo de transformação e aumento da competição; por isso, sua estrutura e a conduta de seus participantes podem mudar com o tempo. Ademais, como evidenciado por Belaisch (2003), o setor bancário brasileiro ainda não é plenamente competitivo.

Outra recomendação pertinente seria o uso de outras variáveis para a medição dos resultados, como, por exemplo, a satisfação dos stakeholders, ou seja, de outras partes interessadas, pois indicadores financeiros de desempenho limitam muito a análise deste conceito multidimensional.

Como mencionado, para Chakravarthy (1986), a mensuração do desempenho da empresa deve ser feita preferencialmente em caráter multidimensional. Uma revisão adicional da literatura de forma a eventualmente melhorar as dimensões estratégicas e de medição de desempenho utilizadas ou mesmo para sugerir novas variáveis também pode auxiliar na definição de um modelo mais robusto e eventualmente mais fiel à realidade.

O referencial teórico também pode ser aprofundado de forma a identificar a possibilidade de melhorar a definição da matriz teórica de centróides, tornando-a eventualmente mais alinhada com a tipologia de estratégias genéricas, proposta por Porter. Por fim, pode-se ainda recomendar o uso de intervalos temporais mais amplos na medição tanto das variáveis estratégicas quanto de desempenho, com o objetivo de reduzir um possível viés que possa ser encontrado na escolha de um único ano. 


\section{REFERÊNCIAS}

ALMEIDA, L. C.; SILVA, J. F.; ALMEIDA JR, R. B. Alianças estratégicas e a indústria financeira brasileira: impactos das estratégias colaborativas e competitivas no desempenho dos bancos comerciais, múltiplos e de investimento. In: ENCONTRO NACIONAL DA ANPAD, 22, 1998, Foz do Iguaçu. Anais... Foz do Iguaçu: ANPAD, 1998. 1 CD-ROM

ANDREWS, K. R. The concept of corporate strategy. Homewood, Illinois: Irwin, 1971.

ANSOFF, H. I. Concept of strategy. In: QUINN, J. B.; MINTZBERG, H.; JAMES, R. M. The strategy process: concepts, contexts and cases. New Jersey: Prentice Hall, 1988. p. 9-13.

ASSAF NETO, A. Estrutura e Análise de Balanços, Um Enfoque EconômicoFinanceiro. 6.ed. São Paulo: Atlas, 2001.

BARNEY, J. B. Gaining and sustaining competitive advantage. Upper Saddle River: Prentice Hall, 2001.

BELAISCH, A. Does Brazilian Banks Compete? IMF Working Paper. WP/03/113, May, p. 1-21, 2003

CARDOSO, F. H.; Mensagem ao Congresso Nacional: abertura da $4^{\text {a }}$ Sessão Legislativa Ordinária da 51a Legislatura, Coleção Documentos da Presidência da República, Brasília: Presidência da República, Secretaria de Comunicação de Governo, 2002, 584p. Disponível em: < http: // www . planalto . gov . br / publi_04 / mensagem2002. htm > Acesso em: 10 set. 2008.

CAVES, R.; PORTER, M. From entry barriers to mobility barriers. Quaterly Journal of Economics, v. 91, 2, pp. 241-261, 1977.

CHAKRAVARTHY, B. S. Measuring strategic performance. Strategic Management Journal, v. 7, p. 437-458, 1986.

HILD, J. Organizational structure, environment and performance: the role of strategic choice. Sociology, v.6, p.1-22,1972.

COOL, K.; DIERICKX, I. Rivalry, strategic groups and the firm profitabily. Strategic Management Journal, v. 9, 3, p 207-223, 1993.

COOL, K.; SCHENDEL, D. Performance differences among strategic group members. Strategic Management Journal, v. 9, 3, p. 207-233, 1998.

DESS, G. G.; DAVIS, P. S. Porter's (1980) Generic Strategies as Determinants of Strategic Group Membership and Organizational Performance. Academy of Management Journal, v. 27, 3, p. 467-488, set. 1984.

FAHEY, L., Gestão estratégica: o desafio empresarial mais importante da atualidade. 
In: FAHEY, L.; RANDALL, R. M. MBA curso prático: estratégia. 2.ed. Rio de Janeiro: Campus, 1999. p. 15-63.

FIEGENBAUM, A., THOMAS, H. Industry and strategic group dynamics: competitive strategy in the insurance industry. Journal of Management Studies, v. 30, 1, pp. 69-105, 1993.

FORTUNA, E. Mercado Financeiro: Produtos E Serviços. Rio de Janeiro: Qualymark. 2001

FOSS, N. J. Research in strategy, economics, and Michael Porter. Journal of Management Studies, v. 33, 1, p. 1-24. 1996.

GIMENEZ, F. A. P., PELISSON, C., KRÜGER, E. G. S., HAYASHI JÚNIOR, P. Estratégia em pequenas empresas: uma aplicação do modelo de Miles e Snow. In: ENCONTRO NACIONAL DA ASSOCIAÇÃO DOS PROGRAMAS DE PÓSGRADUAÇÃO EM ADMINISTRAÇÃO, 22., 1998. Anais..., 1998.

HAMBRICK, D. Taxonomic approaches to studying strategy: some conceptual and methodological issues. Journal of Management, v. 10, 1 p. 27-41, 1984.

HATTEN, K. J.; SCHENDEL, D. E.; COOPER, A. C. A strategic model of the US brewing industry: 1952-1971. Academic Management Journal, v. 21, 4, p. 592-610, 1978.

HAIR, J. F. et al. Análise muitivariada de dados. 5.ed. Porto Alegre: Bookman, 2005.

HOFER, C. W.; SCHENDEL, D. E. Strategic management: a new view of business policy and planning. Canada: Little, Brown \& Company, 1978.

HUNT, M. S. Competition in the major home appliance industry, 1960-1970. Ph.D. Dissertation, Harvard University, 1972.

McGEE, J., AND THOMAS, H. Strategic groups: Theory, research and taxonomy.

Strategic Management Journal, 7, p. 141-160, 1986.

MEHRA, A. Resource and market based determinants of performance in the U.S. banking industry. Strategic Management Journal v. 17, 4, p. 307-322, 1996.

MILES, R. E.; SNOW, C. C. Organizational strategy, structure and process. New York : McGraw-Hill, 1978.

Morgan RE \& Strong CA (1998). Market Orientation and Dimensions of Strategic Orientation. European Journal of Marketing, 32 (11/12), 1051-1073.

MINTZBERG, H. Five Ps for Strategy: the strategy process concepts, contexts and cases, New Jersey: Prentice Hall, 1998.

NAIR, A., KOTHA, S., Does Group Membership Matter? Evidence from the Japanese Steel Industry. Strategic Management Journal, v.22, n.3, p.221-235, 2001. 
PETERAF, M. A. The cornerstones of competitive advantage: a resource-based view. Strategic Management Journal, v. 14, p. 179-188, 1993.

PETERAF, M.; SHANLEY, M. Getting to know you: a theory of strategic group identity. Strategic Management Journal. v. 18. Summer special issue, 1997.

PORTER, M. E. Estratégia competitiva: técnicas para análise de indústria e da concorrência. Rio de Janeiro: Editora Campus, 1980.

. Competitive advantage. New York: Free Press, 1985. v.1.

. What is strategy. Harvard Business Review, v. 74, n. 6. 1996.

PRAHALAD, C. K.; HAMEL, G. Competindo pelo futuro: estratégias inovadoras para obter o controle do seu setor e criar os mercados de amanhã. Rio de Janeiro: Campus, 1990.

THOMAS, H.; VENKATRAMAN, N., Research on strategic groups: Progress and prognosis, Journal of Management Studies, v.25, 6, p.537-555, 1988

VERGARA, S. C. Projetos e relatórios de pesquisa em administração. São Paulo: Atlas. 1997.

WERNERFELT, B. A resource-based view of the firm. Strategic Management Journal, V. 5, 2, p. 171-180, 1984.

WORLD BANK. The Industry Structure of Banking Services, Eduardo Urdapilleta, No 40076-BR, Junho, 2007. 


\section{ENDEREÇO DOS AUTORES:}

\section{Tomas Sparano Martins}

Phil Young Formação Educacional

Rua Rodrigues Alves, 100 - Batel

Curitiba, PR - Brasil

$80240-460$

\section{June Alisson Westarb Cruz}

Phil Young Formação Educacional

Rua Rodrigues Alves, 100 - Batel

Curitiba, PR - Brasil

$80240-460$

\section{Heitor Takashi Kato}

Pontifícia Universidade Católica do Paraná

Centro de Ciências Sociais Aplicadas, Programa de Mestrado Em Administração.

Rua Imaculada Conceição, 1155 - Bloco Acadêmico - $2^{\circ}$ andar, sala 217 - Prado Velho Curitiba, PR - Brasil

80215-901

\section{Wesley Vieira da Silva}

Pontifícia Universidade Católica do Paraná

Centro de Ciências Sociais Aplicadas, Doutorado em Administração Estratégica.

Rua Imaculada Conceição, 1155

Prado Velho

Curitiba, PR - Brasil

80215-901

\section{Eduardo Damião da Silva}

Pontifícia Universidade Católica do Paraná

Centro de Ciências Sociais Aplicadas, Programa de Mestrado Em Administração.

Rua Imaculada Conceição, 1155 - Bloco Acadêmico - Prado Velho

Curitiba, PR - Brasil

80215-901 